\title{
RESULTS OF SURGICAL TREATMENT OF PAEDIATRIC DIAPHYSEAL FRACTURES OF LONG BONES USING INTRAMEDULLARY ELASTIC NAIL
}

\author{
Arun Kumar C1, Gopinath K. $M^{2}$, Roshan Kumar B. $N^{3}$ \\ ${ }_{1}^{1}$ Resident, Department of Orthopaedics, Rajarajeswari Medical College \& Hospital, Bangalore. \\ ${ }^{2}$ Associate Professor, Department of Orthopaedics, Rajarajeswari Medical College \& Hospital, Bangalore. \\ 3 Professor and HOD, Department of Orthopaedics, Rajarajeswari Medical College \& Hospital, Bangalore.
}

\section{ABSTRACT}

\section{BACKGROUND}

Among the various methods of treating the long bone fractures in children less than 5yrs (POP cast) and adolescents 16yrs (IMN), flexible intramedullary nail has gained importance because of its stability, not violating the physis and less complications and early rehabilitation. Irrespective of mode of treatment, goal shall be to achieve union at fracture site, control length and alignment, minimize the morbidity and complications for patient and their family.

\section{MATERIALS AND METHODS}

A prospective study was conducted on children of both sexes, between the age group of 5-15yrs with diaphyseal fractures of long bones, meeting the inclusion and exclusion criteria during the study period at RRMCH (September 2012 to September 2014). Totally, 30 cases were evaluated clinically and radiologically and followed up at 3, 6, 12, 24 weeks after surgery. Final outcome was assessed using Flynn's criteria for Tens Scoring System.

\section{RESULTS}

Results of entire, 30 patients were followed up for an average of 6 months, was excellent in 19(63\%) cases and satisfactory in $11(37 \%)$ cases and no poor outcome.

\section{CONCLUSION}

Based on this study and result, we found that intramedullary elastic nailing technique is an ideal method for treatment of pediatric femoral and tibial diaphyseal fractures.

\section{KEYWORDS}

Intramedullary Elastic Nailing, Diaphyseal Fractures, Femur, Tibia, Immobilisation, Weight Bearing.

HOW TO CITE THIS ARTICLE: Arun Kumar C, Gopinath KM, Kumar RBN. "Results of surgical treatment of paediatric diaphyseal fractures of long bones using intramedullary elastic nail." Journal of Evolution of Medical and Dental Sciences 2015; Vol. 4, Issue 103, December 24; Page: 16822-16826, DOI: 10.14260/jemds/2015/2525

\section{INTRODUCTION}

The goal of the treatment of diaphyseal fracture of long bones in children is to stabilize the fracture, to control the length and alignment to promote the bone healing and minimize the morbidity and complications in the child and family. Treatment of diaphyseal fractures of femur in children has changed since 1982, when Métaizeau and the team from Nancy, France, developed the technique of Elastic Stable Intramedullary Nail (ESIN) using titanium nail.

Surgical treatment of long bone fractures in children must first consider the fact that excellent results can be achieved with non-operative care with reported union rates of more than $90 \%$ and $100 \%$ full functional recovery. ${ }^{1}$ Occasionally, reduction cannot be maintained due to excessive shortening, angulation or malrotation at the fracture site making operative intervention necessary. ${ }^{2}$ Historically external fixation, plate and screw fixation were the treatment options available for those unstable fractures. ${ }^{1,2}$

\section{Financial or Other, Competing Interest: None.}

Submission 07-12-2015, Peer Review 08-12-2015,

Acceptance 19-12-2015, Published 22-12-2015.

Corresponding Author:

Dr. Gopinath K. M,

Associate Professor,

Department of Orthopaedics,

Rajarajeswari Medical College \& Hospital,

Bangalore.

E-mail: drgopinath75@yahoo.com

DOI:10.14260/jemds/2015/2525
Over recent years, the use of elastic stable intramedullary nails has dramatically increased with the introduction of a variety of nails for pediatric fractures. ${ }^{3}$

The Titanium Elastic Nail or Elastic Stable Intramedullary nailing is intended for fixation of diaphyseal fractures of long bones where the medullary canal is narrow or flexibility of the implant is paramount. In pediatric applications, the TENS allows it to be inserted at a point which avoids disruption of the growth plate. The use of an intramedullary device is indicated for open fractures, unstable fractures or irreducible fractures. The aim of this biologically minimally invasive fracture treatment is to achieve a level of reduction and stabilization that is appropriate to the age of the child.

The biomechanical principle of the TEN is based on the symmetrical bracing action of 2 elastic nails inserted into the metaphysis, each of which bears against the inner bone at three points. 4,5 This produces the following four properties that are essential for acheiving optimal results: flexural, axial, translational and rotational stability. ${ }^{4}$ The intramedullary nail also has the advantage of immediate stability which permits early mobilization and faster return to normal activities with low complication rate.6,7

\section{OBJECTIVES OF THE STUDY}

To demonstrate the efficacy of using elastic intramedullary nail in achieving union of pediatric diaphyseal fracture as a less invasive and highly efficient method of treatment in pediatric diaphyseal fractures of long bones. 


\section{MATERIALS AND METHODS}

This is a prospective study based on patients admitted with diaphyseal fractures of long bones in the age group of 5-15 years in Department of Orthopaedics, RRMCH. The duration of study was 2 years (September 2012 to September 2014). Children meeting the Inclusion and Exclusion criteria were included for the study.

\section{Inclusion Criteria}

All children between ages 5 to 15 years having following type of diaphyseal fractures of long bones.

- Closed undisplaced.

- Closed displaced.

- Closed comminuted fractures.

- Closed segmental fractures.

\section{Exclusion Criteria}

- All open fractures having secondary infections or suspected deep infections or late presentations.

- Closed fractures more than 2 weeks old.

- All metaphyseal fractures with/without involvement of epiphysis.

- All pathological fractures.

- $\quad$ Parents/patient not willing for surgery.

Children suffering from epilepsy, heart diseases, neuromuscular diseases and bleeding diathesis is excluded from our study.

After informed consent and routine preoperative workup, surgery was performed under general/spinal anaesthesia with patient on fracture table in supine position for femur fracture and on regular operating table for tibia fracture. The diameter of the individual nail was selected as per Flynn et al. formula (Diameter of nail $=$ width of the narrowest point of medullary canal on AP and lateral view $\mathrm{x} 0.4 \mathrm{~mm}$ ) and intraoperative assessment. The diameter of the nail was chosen, so that each nail occupies at least 33\%-40\% of the medullary cavity. The usual procedure for TENS nailing of Diaphyseal fracture of Femur (Retrograde fixation) and Tibia (Antegrade fixation) under fluroscopic guidance was done.

To minimise soft tissue irritation nails are backed out and cut along the metaphysis and a tamp is used to readvance the implants until $<1 \mathrm{~cm}$ of nail lies outside. Postoperatively, patients are nursed in supine position with operated leg elevated on a pillow with long leg slab/cast and pelvic band for femur fracture or above knee slab/cast for tibia fracture for 6 weeks and immobilisation was continued for another 2-3 weeks based on radiological assessment. Full weight bearing was started by 8-12 weeks depending on fracture configuration and callus response. Assessment was done at 6 , 12 and 24 weeks and each followup patients are assessed clinically, radiologically and complications were noted.

\section{OPERATIVE PHOTOGRAPHS OF FEMUR}

Case 1
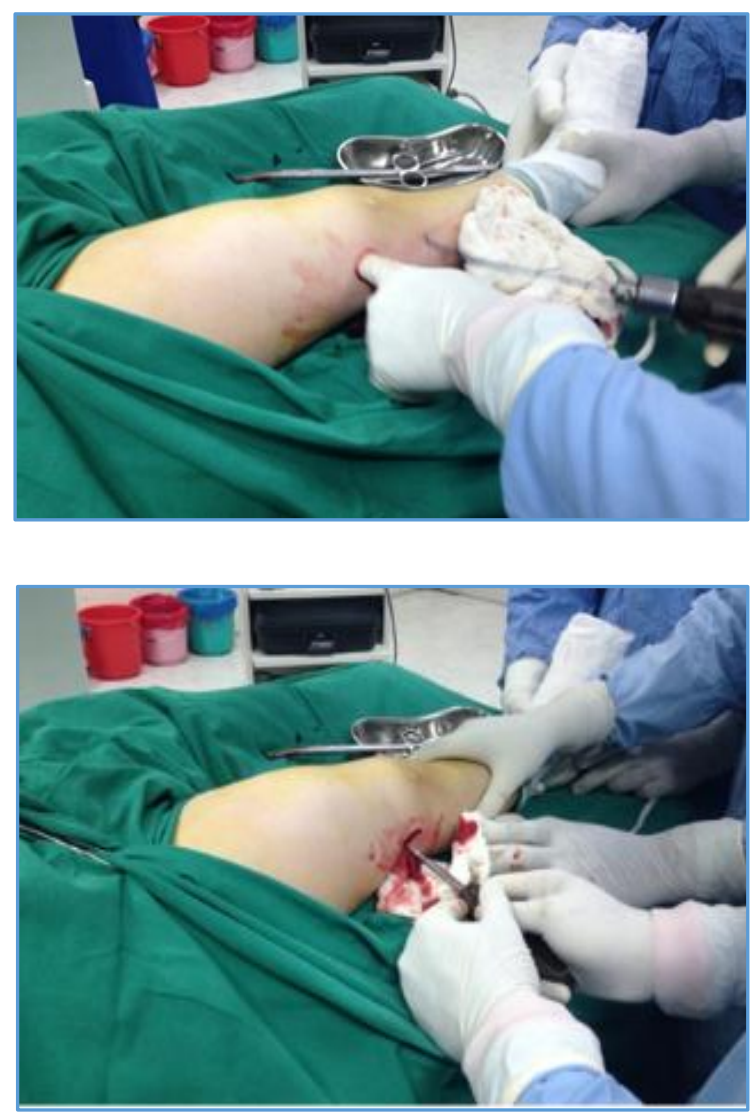

Incision

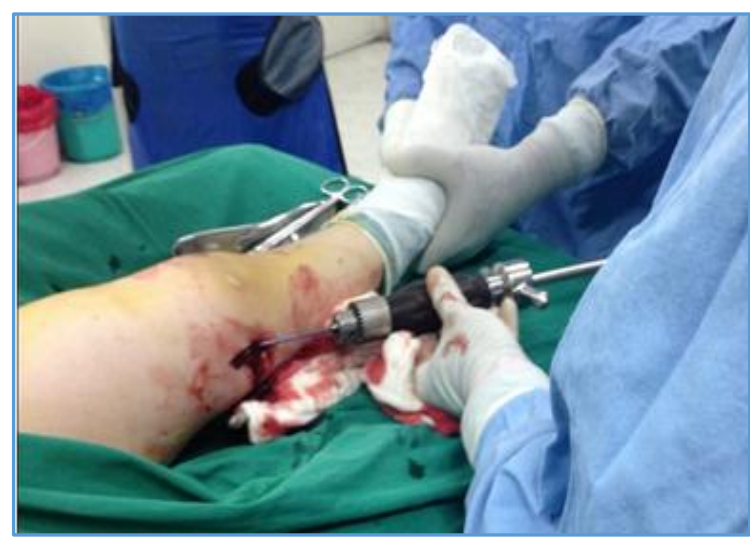

Incision and entry point made with bone $A W L$
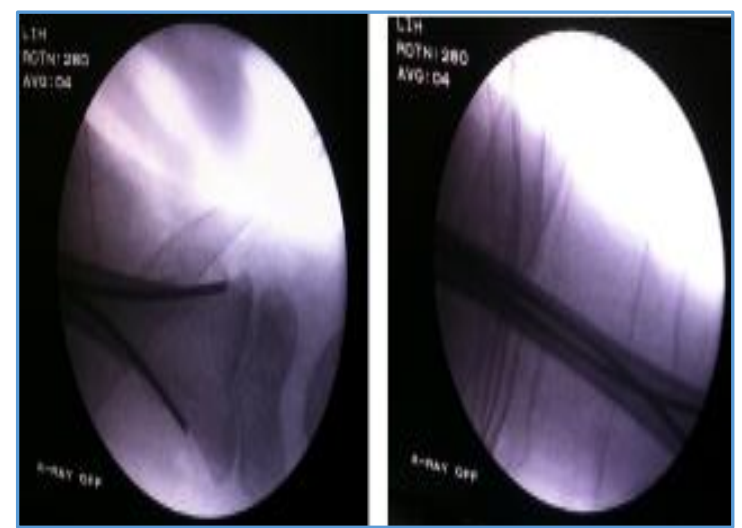

Introduction of TENS nail 


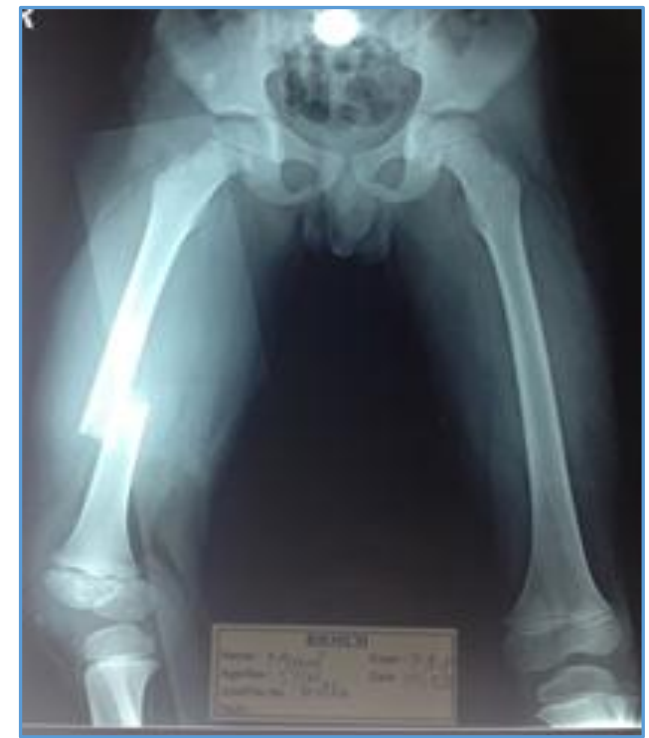

Preoperative X-ray

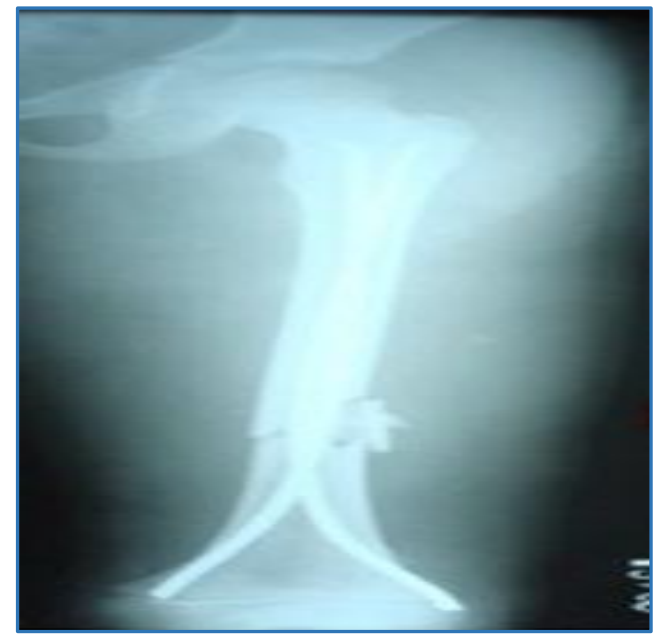

Post Op 16 weeks

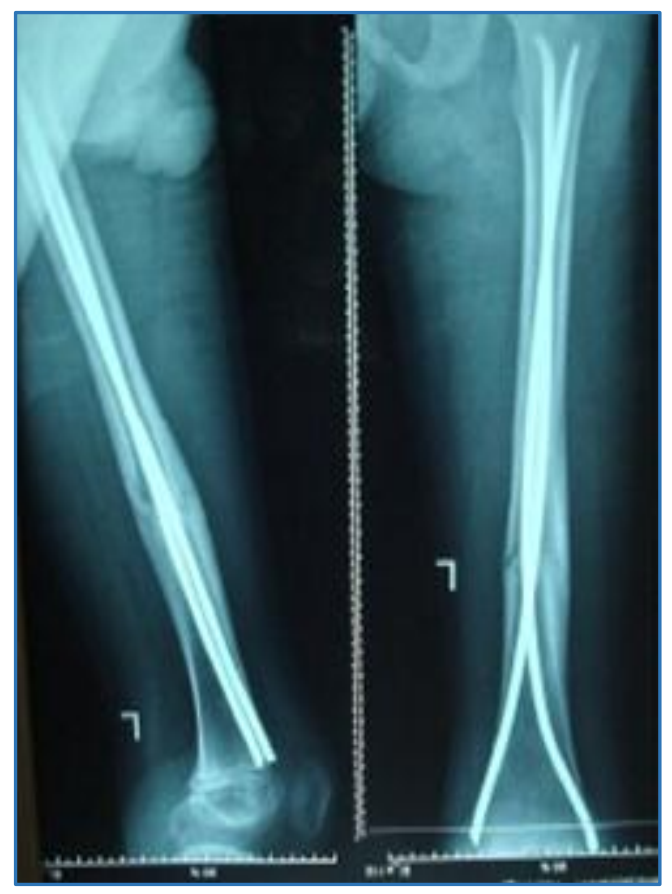

Post Op 24 weeks
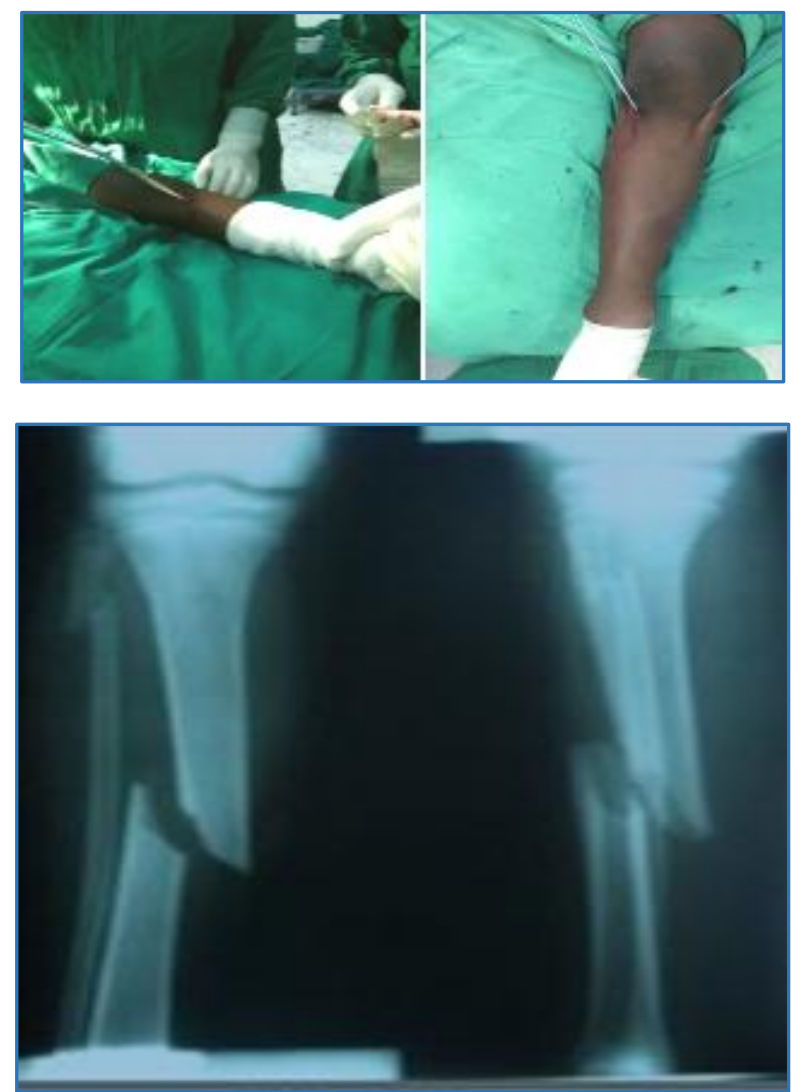

Preoperative

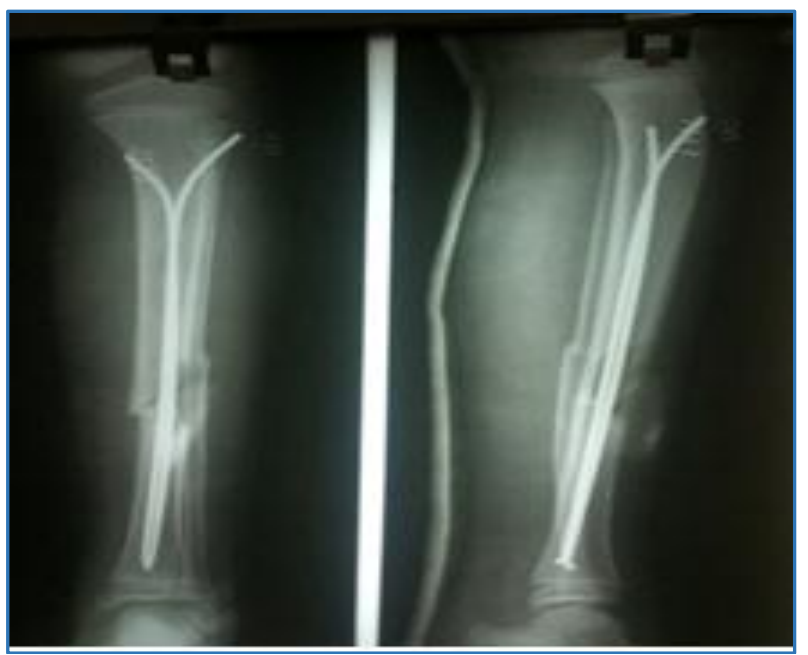

Post Op 12 weeks

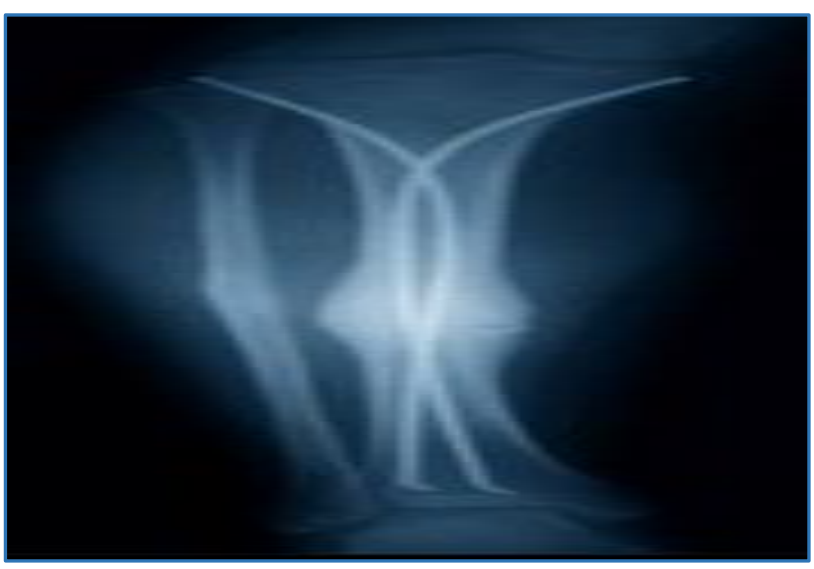

Post Op 24 weeks 


\section{RESULTS}

Thirty patients with diaphyseal fracture of femur (17) and tibia (13) were treated with titanium intramedullary elastic nail between Sep 2012 - Sep 2014 at RRMCH, Bangalore. Children between the age group 5-15yrs were included in the study; 21 patients (70\%) were male and 9 patients (30\%) females. Road traffic accidents was the most common mode of injury accounting for $57 \%$ (17 patients) and self-fall the next to RTA-36\%(11 patients). Among the 30 patients, 57\%(17) had sustained fracture to the left side and $43 \%(13)$ had on right side. Transverse fracture were about $10(33 \%)$ comminuted were $7(23 \%)$, oblique fractures $8(27 \%)$ and spiral fracture $5(17 \%)$. All the patients were prepared and operated as early as possible once the general condition was stable and patient was fit for surgery. The average time interval between the fracture and surgery was 3.6 days with $10(33 \%)$ within 5 days, $10(33 \%)$ less than 2 days $8(27 \%)>5$ days $2(7 \%)$. The median duration of surgery was $65.5 \mathrm{~min}(30-110)$. Out of 30 patients, $22(73 \%)$ has been immobilized for 6 weeks and $8(27 \%)$ for 9 weeks. Average duration of hospital stay was 9.9 days (3-17); $90 \%$ (27) had $<1 \mathrm{cms}$ of limb length discrepancy and 3 patients $(10 \%)$ less than $2 \mathrm{cms}$. Union was achieved in 25(84\%) within 12 wks. and full weightbearing was allowed for 24(80\%) within 12 weeks. All patients had full range of movements in this study, 6(20\%) had mild restriction at knee at 12 weeks. No patient had major limb length discrepancy $(>2 \mathrm{cms})$ in this study. No nail back-out was seen in this study. Superficial infection was seen in 5 patients $(24 \%)$ and 3 patients had limb length discrepancy (9.82\%) and no patients had major limb length discrepancy, i.e. $> \pm 2 \mathrm{cms}$ and 3 patients (10\%) presented with 6 degree valgus deformity and no patient had anteroposterior malalignment.

\section{DISCUSSION}

Until recently conservative treatment was the preferred method for the treatment of diaphyseal fractures in children and young adolescents. However, to avoid the effects of prolonged immobilisation to reduce the loss of school days and for better nursing care, the operative approach has been gaining popularity for the last two decades. Plate osteosynthesis is still widely used. It is associated with a large exposure, relatively longer duration of immobilisation and the risks of delayed union, infection and a large dissection for plate Removal., ${ }^{8,9}$ The external fixator provides good stability and early mobilisation, but is associated with the risk of pin tract infections and it takes a longer time for weightbearing. ${ }^{10,11}$ Intramedullary K-wire fixation has also been used for pediatric femoral fracture, but stability and fracture angulation is a disadvantage to be taken care of. Interlocking nail is ideal for skeletally matured children. Reports of avascular necrosis of femoral head, coxa valga have been reported with interlocking nail when attempted in skeletally immature patients. ${ }^{12,13}$ However, there have been proponents for using interlocking nail in the 11-16 years of age group avoiding the pyriformis fossa as entry site with good results. ${ }^{14}$ Titanium elastic nail seems advantageous over other surgical method, particularly in this age group because it is simple, is a load sharing internal splint that does not violate the physis, allows early mobilisation and maintains alignment. Micromotion conferred by the elasticity of the fixation promotes faster external bridging callus formation. The periosteum is not disturbed and being a closed procedure there is no disturbance of the fracture haematoma, thereby less risk of infection. Flynn et al. found TEN advantageous over hip spica in treatment of femoral shaft fractures in children. ${ }^{15}$ Bueschsenschuetz et al., documented titanium nail superior in terms of union, scar acceptance and overall patient satisfaction compared to traction and casting. ${ }^{16}$ Ligier et al. treated 123 femoral shaft fractures with elastic stable intramedullary nail. All fractures united; 13 children developed entry site irritation. ${ }^{17}$ Similarly, Narayanan et al. found good outcome in 79 femoral fractures stabilised with TEN. ${ }^{18}$ Fracture geometry and the location is an important determinant for selection of surgical techniques. Transverse, short oblique and minimally comminuted are suitable for TEN as stated by Flynn et al. ${ }^{19}$ Narayanan et al. ${ }^{18}$ stated that transverse, short oblique, short spiral fractures with minimum comminution in the 5-12 years age group were the best indications for TEN. Lascombes et al. ${ }^{20}$ stated that TEN could be indicated in all femoral diaphyseal fractures of children above 6 years of age till epiphysis is closed except severe type 3 open fractures. The most common complication of titanium elastic nail is entry site irritation and pain. ${ }^{18,21}$ Entry site irritation was found in $4(19 \%)$ cases. Limb length discrepancy is a common sequel; $2(7 \%)$ patients had shortening of femur $<1 \mathrm{~cm}$ and $1(3 \%)$ had shortening of femur $<2 \mathrm{cms}$. Other complications include angulation of fracture, refractures and infection. Superficial infection was found in $1(5 \%)$ case.

\section{CONCLUSION}

Based on this study and result, we found that intramedullary elastic nailing technique is an ideal method for treatment of pediatric femoral and tibial diaphyseal fractures.

\section{REFERENCES}

1. El-Adl G, Mostafa MF, Khalil MA, et al. Titanium elastic nail fixation for paediatric femoral and tibial fractures. Acta Orthop Belg 2009;75:512-520.

2. Sankar WN, Jones KJ, David Horn B, et al.: Titanium elastic nails for pediatric tibial shaft fractures. J Child Orthop 2007;1:281-286.

3. Helenius I, Lamberg TS, Kääriäinen S, et al.: Operative treatment of fractures in children is increasing. A population-based study from Finland. J Bone Joint Surg Am 2009;91:2612-2616.

4. Li Y, Stabile KJ, Shilt JS: Biomechanical analysis of titanium elastic nail fixation in a pediatric femur fracture model. J Pediatr Orthop 2008;28:874-878.

5. Mahar A, Sink E, Faro F, et al.: Differences in biomechanical stability of femur fracture fixation when using titanium nails of increasing diameter. J Child Orthop 2007;1:211-215.

6. Pogorelic' Z, Furlan D, Bioc ${ }^{\prime} i c^{\prime} M$, et al.: Titanium intramedullary nailing for treatment of simple bone cysts of the long bones in children. Scott Med J 2010;55:35-38.

7. Wall EJ, Jain V, Vora V, et al.: Complications of titanium and stainless steel elastic nail fixation of pediatric femoral fractures J Bone Jt Surg Am 2008;90:1005-1010.

8. Reeves RB, Ballard RJ, Hughes JL, et al. Internal fixation versus traction and casting of adolescent femoral shaft fractures. J pediatr Orthop 1990;10:592-5.

9. Ward WT, Levy J, Kaye A. Compression plating for child and adolescent femur fractures. J Pediatr orthop 1992;12:626-32. 
10. Aronson J, Torsky EA. External fixation of femur fractures in children. J pediatr orthop 1992;12:157-63.

11. Krettek C, Haas N, Walker J, et al. Treatment of femoral shaft fracturs in children by external fixation. Injury 1991;22:263-6.

12. Beaty JH, Austin SM, Warner WC, et al. Interlocking intramedullary nailing of femoral shaft fractures in adolescents: Preliminary results and complications. J pediatr Orthop 1994;14:178-83.

13. Letts M, Jarvis J, Lawton L, et al. Complications of rigid intramedullary rodding of femoral shaft fractures in children. J trauma 2002;52:504-16.

14. Buford D, Christensen K, Weather P. Intramedullary nailing of femoral fractures in adolescents. Clin Orthop Relat Res 1998;350:85-9.

15. Flynn JM, Luedtke LM, Theodre J, Ganley TJ, Dawson J, Davidson RS, et al. Comparison of titanium elastic nails with traction and a spica cast to treat femoral fractures in children. J Bone Joint Surg Am 2004;86:770-7.

16. Buechsenschuetz KE, Mehlman CT, Shaw KJ, et al. Femoral shaft fractures in children: traction and casting versus elastic stable intramedullary nailing. J trauma 2002;53:914-21.
17. Ligier JN, Metaizeau JP, Prevot J, et al. Elastic stable intaramedullary nailing of femoral shaft fractures in children. J Bone Joint Surg Br 1988;70:74-7.

18. Narayanan UG, Hyman JE, Wainwright AM, et al. Complications of elastic stable intramedullary nail fixation of pediatric femoral fractures and How to avoid them. J Pediatr Orthop 2004;24:363-9.

19. Flynn JM, Skaggs DL, Sponseller PD, Ganley TJ, Kay RM, Kellie Leitch KK. The operative management of pediatric fractures of the lower extremity. J Bone Joint Surg Am 2002;84:2288-300.

20. Lascombes P, Haumont T, Journeau P. Use and abuse of flexible intramedullary nailing in children and adolescents. J Pediatr Orthop 2006;26:827-34.

21. Flynn JM, Hresko T, Reynolds RA, Blasier RD, Davidson $\mathrm{R}$, Kasser J. Titanium elastic nails for pediatric femur fractures: A multicenter study of early results with analysis of complications.

J Pediatr Orthop 2001;21:4-8. 